J. Lake Sci. ( 湖泊科学 ), 2006, 18( 1 ):57 -62

http:// www. jlakes. org. E-mail: jlakes@ niglas. ac.cn

(c) 2006 by Journal of Lake Sciences

\title{
我掌河泥石流对四川邛海影响的初步研究”
}

\author{
余斌，王士革，章书成，孟国才 \\ ( 中国科学院成都山地灾害与环境研究所, 成都 610041 )
}

摘 要: 沉积作用在湖泊的演化和消亡过程中至关重要, 洪水泥石流的淤积作用对我国西南地区广泛分布的构造断陷湖 泊是一个普遍的环境问题. 通过调查鹅掌河泥石流发育背景, 人类的活动对泥沙进人扔海的影响和对比 1988 年与 2003 年扔海水下地形图得出: 在近 30 年的时间内, 我掌河洪水和泥石流改沿固定河堤流人扔海, 在湖底形成浊流, 将更大量 泥沙带到湖中. 浊流在鹅掌河河口的水下扇陡坡上形成一水下冲沟,在湖底沉积区形成一条长 $2 \mathrm{~km}$ 的水下堤. 计算发现, 我掌河泥石流带人扔海的泥沙远大于一般土壤侵蚀产沙量, 其中 以 1996, 1997 和 1998 三年泥石流输人的泥沙量最多. 我鸟掌河洪水和泥石流对巧海的影响以及水下地形、湖泊基本特征和湖泊环境的变化,应引起人们对扔海保护的高度关注. 关键词: 泥石流; 卭海; 泥沙; 水下堤

\section{Preliminary study on the effect of debris flows from Goose Foot River on Lake Qionghai, Sichuan, China}

\author{
YU Bin, WANG Shige, ZHANG Shucheng \& MENG Guocai \\ ( Institute of Mountain Disaster and Environment, Chinese Academy of Sciences, ,Chengdu 610041, P. R. China)
}

\begin{abstract}
Aggradations are very important for the developing and dying-out of lakes. The aggradations of floods and debris flows are common environmental problems in fault lakes in southwestern China. Investigating the background of the basin of Goose Foot River, the effect of human activities on Lake Qionghai, Sichuan Province, China, and the underwater topography maps of 1988 and 2003 were analyzed. In the past 30 years, turbidity currents were formed by debris flows and floods of Goose Foot River and took huge sediment into Lake Qionghai. The sediment not only pushed the coastline of Lake Qionghai at Goose Foot River fan into lake, but also deposited in the lake to the opposite bank. Debris flows took much more sediment into Lake Qionghai than the soil erosion did in the same basin. There is an underwater levee on the underwater fan. The underwater levee is $2 \mathrm{~km}$ in length, $200 \mathrm{~m}$ ( at south coast ) to $600 \mathrm{~m}$ ( at north coast) in width and the average $2 \mathrm{~m}$ in height. The maximum height of sediment deposition at underwater levee is $8.29 \mathrm{~m}$, or $0.55 \mathrm{~m}$ for every year. There is a channel on the slope of the underwater fan of Goose Foot River mouth eroded by turbidity currents. The main source of sediment is the sediment token by the debris flows in 1996, 1997 and 1998. It should be paid more attention on the environment issues, such as basic characteristics, underwater topography of Lake Qionghai and the effect of Goose Foot River debris flows on Lake Qionghai.
\end{abstract}

Keywords: Debris flow; Lake Qionghai; sediment; underwater levee

湖泊是地球表面上暂时存在的地质体，因为不管湖泊是由哪一种强烈的地质事件，如火山，地震或冰 川作用形成的, 如果湖泊地区不再发生大的构造变动, 湖泊将在适当的时候被沉积物所填充而转变为陆 地 ${ }^{[1]}$. 断陷湖泊的形成和演化也要经历早期拉张裂开, 中期深陷扩张和晚期充填收缩三个阶段 ${ }^{[2]}$. 因此沉 积作用在湖泊的演化和消亡过程中至关重要. 洪水泥石流的淤积作用对我国西南地区广泛分布的构造断 
陷湖泊是一个普遍的环境问题.

邛海位于四川省凉山彝族自治州西昌市东南郊, 地理位置: 东经 $102^{\circ} 15^{\prime}-102^{\circ} 18^{\prime}$, 北纬 $27^{\circ} 42^{\prime}-27^{\circ}$ $55^{\prime}$ 之间, 属高原构造淡水湖泊, 面积 $27.41 \mathrm{~km}^{2}$, 集水面积 $307.67 \mathrm{~km}^{2}$, 为四川省第二大天然湖泊和当地工 农业生产重要的水源地. 邛海 - 泸山风景区又是四川省十大风景区之一, 2002 年扔海 - 螺䯵山被列为国家 重点风景名胜区. 扔海流域地处青藏高原东南缘横断山纵谷区, 气候受西南季风环流控制, 属我国西南亚 热带高原山区. 邛海湖盆为断层陷落盆地, 东、北、南三面被高山环绕, 山地海拔在 $1507 \mathrm{~m}-3263 \mathrm{~m}$ 间, 西 与安宁河谷相连. 流人扔海的较大河流有 8 条, 其中以官坝河流域面积最大 $121.60 \mathrm{~km}^{2}$, 我掌河次之. 扔 海流域的土壤侵蚀主要源于官坝河和我掌河等 8 条河流, 每年土壤侵蚀总量 $2.94 \times 10^{5} \mathrm{~m}^{3}$, 其中官坝河流 域占 $53.8 \%$, 我掌河流域占 $23.08 \%$. 邛海的出流位于湖泊西北部, 湖水由海河人安宁河后汇人金沙江 ${ }^{1}$.

邛海曾进行三次水下地形测量, 1952 年原西康省水利局实测邛海水下地形, 南北长 $11.5 \mathrm{~km}$, 东西宽 $5.5 \mathrm{~km}$, 湖面面积 $31 \mathrm{~km}^{2}$, 最大水深 $34 \mathrm{~m}$, 平均水深 $14 \mathrm{~m}$, 蓄水量 $3.2 \times 10^{8} \mathrm{~m}^{3} ; 1988$ 年攀西地质大队再次 作水下地形实测. 第三次于 2003 年 8 月由云南省环境科学研究所与昆明理工大学测绘技术研究所实测, 邛 海湖面面积 $27.41 \mathrm{~km}^{2}$, 最大水深 $18.32 \mathrm{~m}$, 平均水深 $10.95 \mathrm{~m}$, 蓄水量 $2.93 \times 10^{8} \mathrm{~m}^{3}$, 表明 50 年来扔海的湖 泊的基本特征发生明显变化. 又据 $1962-2002$ 年邛海水位站资料, 邛海历年最低水位 $1509.05 \mathrm{~m}$ (黄海基准 水位, 下同 ),历年最高水位 $1511.77 \mathrm{~m}$, 最大水位变幅 $2.72 \mathrm{~m}$.

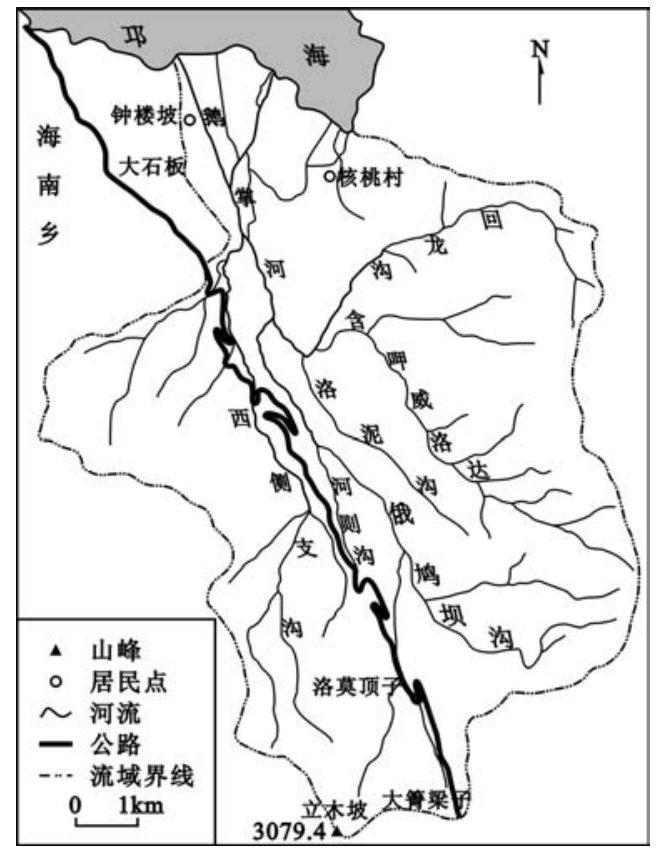

图 1 鹅掌河流域图

Fig. 1 Basin of Goose Foot River

鹅掌河位于扔海南岸, 流域形状如同带蹼的鹅掌( 图 1 ). 鹅掌河源于大箐梁子北坡, 源头海拔 $2590 \mathrm{~m}$ ( 流域内上游分水岭立木坡海拔 $3079.6 \mathrm{~m}$, 是邛海流域最高点), 经大箐乡, 大箐林场在海南乡钟楼坡村右 侧人汇扔海. 鹅掌河流域集水面积 $50.14 \mathrm{~km}^{2}$, 主沟长 $13.18 \mathrm{~km}$, 平均纵比降 $119 \%$. 流域水系发达, 溪沟 密布, 长度大于 $1 \mathrm{~km}$ 的支沟 34 条, 其中长度大于 $3 \mathrm{~km}$ 的支沟 12 条, 水系密度达 0.68 条/ $\mathrm{km}^{2}$. 我掌河下

(1) 云南省环境科学研究所, 北京大学环境学院, 中国昆明高原湖泊国际研究中心. 邛海流域环境规划总报告. 2004 年 5 月, $10-19$. 
游山前冲洪积堆积区, 面积 $2.2 \mathrm{~km}^{2}$, 河长 $4.33 \mathrm{~km}$, 纵比降 $37 \%$. 流域中上游为构造剥蚀侵蚀山区, 面积 达 $47.9 \mathrm{~km}^{2}$, 由于受北西向则木河活动断裂与邛海断陷的影响,物源区岩层破碎, 崩塌滑坡等不良地质现象 发育, 泥石流固体物质来源丰富, 一旦有较大降雨, 就可能暴发泥石流 ${ }^{1}$. 流域内年降雨量超过 $1000 \mathrm{~mm}$, 同时降水集中 6-10月雨季,其降水量占全年总量的 $80 \%$ 以上,为泥石流发育提供气候条件. 流域多年平 均径流深 $750 \mathrm{~mm}$, 多年平均流量 $1.2 \mathrm{~m}^{3} / \mathrm{s}$. 鹅掌河河水挟带的泥沙量和泥沙粒径在暴发泥石流时最大. 下 游的泥石流堆积体中, 砾石粒径从 $5 \mathrm{~cm}$ 到 $400 \mathrm{~cm}$; 砾石成分有: 浅黄色沙岩, 砖红色泥质粉沙岩和灰白色 砾岩. 堆积物在靠近扔海湖口地区粒径变小, 以粗沙为主, 也含有磨圆度很好的卵石, 粒径约 $2 \mathrm{~cm}$, 成分 为沙岩, 粉沙岩和砾岩. 在人湖口前扇缘处堆积物以石英为主的细沙, 含少量的泥质. 在平水年, 我掌河 每年输人扔海的泥沙有 $4.96 \times 10^{4} \mathrm{~m}^{3}$.

\section{1 我掌河泥石流活动规律}

我鸟掌河是一条老泥石流沟. 据记载 1843 年曾暴发的泥石流, 将位于海南乡钟楼坡村大石板的村庄淤 埋, 造成不少当时观看川戏的群众死伤，泥石流规模属百年一遇. 在此后的 1949 年、1957 年、1968 年、 1985 年和 1991 年都暴发过小规模的泥石流, 淤埋的农田面积都在 $3.3 \mathrm{hm}^{2}$ 以下, 直接经济损失也低于 6 万元, 但没有造成人员伤亡, 属 10 年一遇. 由于沟口到邛海之间的堆积扇长 $3 \mathrm{~km}$, 小规模的泥石流往往在 沟口前淤积后, 演变成山洪进人邛海. 在自然状况下,我掌河常年暴发的洪水多在扇面上散开,分流后因流 量和流速较小,挟沙能力减弱, 大量泥沙淤积在洪积扇上, 一般不会造成人员伤亡和财产损失, 进人扔海的 泥沙也相对较少. 人类的不合理的生产活动改变鹅掌河流域的状况,使鹅掌河输人扔海的泥沙大增, 扔海湖 面面积和蓄水量日益减小. 人类的不合理的生产活动表现在:第一, 20 世纪 70 年代末期, 原住在高海拔地 区 ( 海拔 3000-3500 m ) 的彝族农民开始下迁, 逐渐移居至洪积扇中上部( 海拔 $2000-2800 \mathrm{~m}$ ), 并且在这 些地方毁林开荒, 现在已达 500 余户,流域内生态环境遭到破坏, 加剧了水土流失, 并导致滑坡泥石流的活 动加剧; 第二, 西巧公路改建及其他工程建设引发的滑坡和工程弃土, 为泥石流提供了大量的固体物质; 第 三,1975 年开始在我掌河的下游修建河堤, 将鹅掌河河水约束在上游段 $26 \mathrm{~m}$, 下游近河口段 $65 \mathrm{~m}$ 宽的河 堤内. 后来由于河床淤积, 又 4 次加高河堤, 堤高已达近 $5 \mathrm{~m}$, 使山洪泥石流集中进入邛海;第四,从 20 世纪 80 年代初期起, 当地居民在我掌河河堤内掏取沙石作为建筑材料, 采沙石成为当地的收人来源之一.

由于在中上游地区的毁林开荒，破坏原生森林植被,造成严重的水土流失和岸坡崩滑，为泥石流提供 更多固体物质, 故近 10 年来鹅掌河泥石流暴发的频率有逐渐增高的趋势. 束窄的河道使河水有较大的单 宽流量, 致使洪水暴发时大量泥沙随洪水注人湖中. 沙石的开采使下游高程降低,造成河床溯源侵蚀, 引 发更多的岸坡崩滑, 为洪水和泥石流提供更多的固体物质. 1996 年鹅掌河左支沟暴发粘性泥石流冲毁河 堤, 大量泥沙淤积在河堤右侧荒地上. 粘性泥石流向前运动逐渐演变成稀性泥石流, 淹没河堤右侧农田, 另一部分由河堤直接输送人扔海, 整个泥石流暴发历时约 5 h. 1997 年暴发泥石流规模稍小. 1998 年暴发 的泥石流源于找掌河主沟, 大流量的泥石流冲出河堤, 淤积在河堤右侧荒地上, 而后变成稀性泥石流淹没 河堤右测农田, 同时在河堤内的泥石流也演变成稀性泥石流直接流人扔海, 整个泥石流暴发历时约 $12 \mathrm{~h}$. 1996，1997 和 1998 连续三年暴发的泥石流尚属中等规模，虽没有造成了人员伤亡，但淤埋的农田面积都 在 $66.7 \mathrm{hm}^{2}$ 上下, 直接经济损失 100 万元左右, 也显示近 10 年来鹅掌河泥石流暴发的频率有逐渐增高的 趋势.

\section{2 我掌河泥石流对扔海的影响}

对比邛海 1957 年和 1984 年我掌河河口附近的水下地形图, 在 $1581 \mathrm{~m}$ 长的对照湖岸线上, 岸线平均 向前推进了 $67 \mathrm{~m}$, 平均推进速度约 $2.5 \mathrm{~m} / \mathrm{a}$. 在 2001 年和 2004 年的 $60.9 \mathrm{~m}$ 长对照湖岸线上, 湖岸线被平 均推进 $6.7 \mathrm{~m}$, 平均每年达 $2.2 \mathrm{~m}$. 经计算没有泥石流发生的年份鹅掌河河口地区的湖岸线平均每年向邛

(1) 地矿部成都水文地质中心. 泥石流灾害防治勘查及综合治理规划报告( 四川省攀西安宁河冕宁 - 德昌段鹅掌 
海进约 $2 \mathrm{~m}$; 有小规模泥石流发生时, 如 1957 年到 1984 年发生过 2 次, 湖岸线向湖中推进速度更快. 图 2 为邛海水下地形对比图及水下断面图 ${ }^{[3]}$. 其中图 $2 b$ 显示 2003 年湖底存在由南到北贯穿邛海湖心两个水 下堤.一条正对官坝河人湖口, 由北向南廷伸 $1 \mathrm{~km}$, 北部宽 $100 \mathrm{~m}$ 到南部增大至 $200 \mathrm{~m}$; 另一条正对鹅掌河 入湖口, 由南到北长 $2 \mathrm{~km}$, 水下沙堤南部宽 $200 \mathrm{~m}$ 向北增宽至 $600 \mathrm{~m}$. 对比 1988 年的水下地形图( 图 $2-$ a ), 虽然该图较 2003 年水下地形图粗糙，但从水下堤位置的水深在 $15-20 \mathrm{~m}$, 而 2003 年的水下堤的水深 分别减小至 $12 \mathrm{~m}$ 和 $14 \mathrm{~m}$ 分析, 加之 1988 年测量时水面高程为 $1509.71 \mathrm{~m}, 2003$ 年测量时水面高程为 1510 $\mathrm{m}$ 判断,水下堤在 15 年间淤高约 $1.29-8.29 \mathrm{~m}$, 证实 2003 年发现的水下沙堤应是这 15 年间形成.
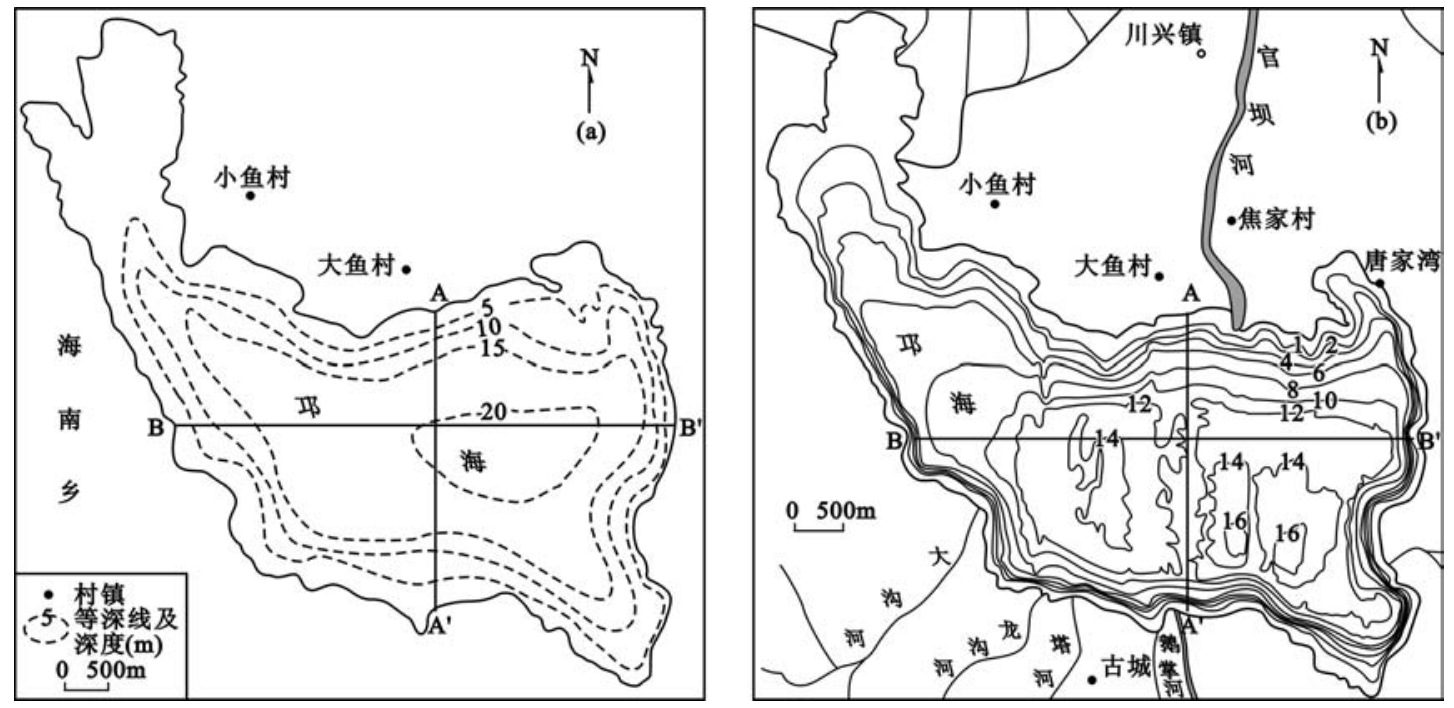

图 2 邛海湖盆地形 ( a:1988 年, 湖面高程 $1509.71 \mathrm{~m} ; \mathrm{b}: 2003$ 年, 湖面高程 $1510 \mathrm{~m}$ )

Fig. 2 Underwater lake basin in Lake Qionghai( a:in 1988, the altitude of water surface is $1509.71 \mathrm{~m}$; b: in 2003 , the altitude of water surface is $1510 \mathrm{~m}$ )

另据图 3,A-A 断面是鹅掌河河口正对邛海的水下堤断面, 2003 年该断面湖底比 1988 年平均高 5.46 $\mathrm{m}$, 如果按水下堤平均宽度 $400 \mathrm{~m}$, 则 $3400 \mathrm{~m}$ 长的水下堤约淤积了 $7.19 \times 10^{6} \mathrm{~m}^{3}$ 泥沙, 加上水下堤两边淤 积的泥沙，估算这 15 年间扔海湖底淤积的泥沙量更多. 而 15 年间扔海流域土壤侵蚀总量仅 $4.41 \times 10^{6}$ $\mathrm{m}^{3}$, 显然鹅掌河 1996, 1997, 1998 连续 3 年暴发的泥石流对扔海淤积的贡献巨大. 鹅掌河常年洪水和泥石 流将泥沙带人邛海, 不仅淤积在河口形成水下堆积扇, 而且含沙量很高的洪水或泥石流还潜人湖底, 形成 浊流在扔海底部继续运动. 据资料, 当河水容重大于 $1.001 \mathrm{~g} / \mathrm{cm}^{3}$ 而湖水容重为 $1.0 \mathrm{~g} / \mathrm{cm}^{3}$ 时就可能发生浊 流; 当河水容重大于 $1.013 \mathrm{~g} / \mathrm{cm}^{3}$ 而湖水容重为 $1.0 \mathrm{~g} / \mathrm{cm}^{3}$ 时浊流就可以保持稳定运动很远的距离; 而对 于更高容重的高含沙洪水或泥石流在湖中则可形成高浓度浊流, 这种浊流在坡度很小的海底可运动数百 甚至上千公里 ${ }^{[4]}$. 浊流在大坡度时还可以侵蚀底坡. 世界许多著名河流在深海扇前不到 $10 \%$ 的坡度下被 浊流侵蚀出沟道形成海底峡谷, 在深海扇上形成沉积型河道 ${ }^{[5,6]}$. 2003 年测量了扔海水下地形后, 潜水员 考察搜索我掌河河口附近湖底时, 发现了一条水下冲沟. 邛海的水下断面的平均坡度为:0 m( 湖岸线 ) -15 $\mathrm{m}: 4 \% ; 15 \mathrm{~m}-25 \mathrm{~m}: 21 \% ; 25 \mathrm{~m}-55 \mathrm{~m}: 5 \% ; 55 \mathrm{~m}-70 \mathrm{~m}: 12 \% ; 70 \mathrm{~m}-310 \mathrm{~m}: 3.3 \%$. 湖底陡坡坡度为 $21 \%$, 远大于深海峡谷的 $10 \%$. 在现在的河口段平均坡度 $0.32 \circ(0.56 \%)$, 因此泥石流或高含沙水流在进入邛海 后底坡反而增大, 浊流加速运动, 侵蚀湖中陡坡形成水下冲沟, 形成浊流在扔海底部继续运动. 云南省断 陷湖泊滇池, 洱海和抚仙湖都有浊流沉积, 其中以抚仙湖浊流运动最为显著, 最远的沉积距浊流发生地达 $9 \mathrm{~km}$, 前缘最终沉积在很小的缓坡或反坡上 ${ }^{[2,7]}$. 世界著名河流 Zaire 河的深海扇上距海岸线 $500 \mathrm{~km}$ 处的 浊流观测仪器置于底坡坡度为 $0.2 \%-0.4 \%$ 的深海海底河道上方 $150 \mathrm{~m}$, 实测浊流流速达 $1.21 \mathrm{~m} / \mathrm{s}$. 尽管 
知道产生如此强大的浊流的源头距观测点很遥远, 但无法建立源头与观测的联系, 因为没有获得包括地 震和洪水在内的任何产生浊流的有关信息 ${ }^{[8]}$, 由于密度的差别产生浊流能运移很长的距离是不容置疑的.

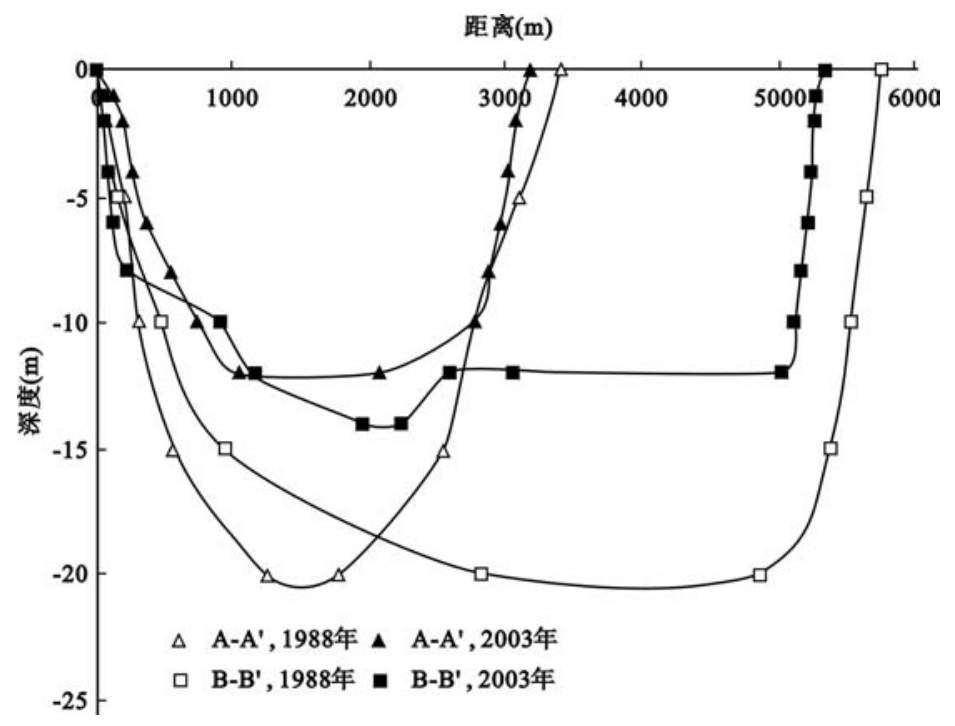

图 3 工海水下地形图

Fig. 3 Underwater profile of Lake Qionghai

我鸟掌河泥石流的容重可以由以下公式计算 ${ }^{[9]}$ :

$$
\begin{aligned}
& C=\frac{\rho \tan \theta}{(\sigma-\rho)(\tan \alpha-\tan \theta)} \\
& \tan \alpha=\left(\frac{C}{C^{*}}\right)^{1 / 6} \tan \varnothing \\
& p_{d}=\rho+C(\sigma-\rho)
\end{aligned}
$$

式中, $C$ 为泥石流饱和浓度; $\sigma$ 为泥沙容重 $\left(2.65 \mathrm{~g} / \mathrm{cm}^{3}\right) ; \theta$ 为泥石流底坡坡度; $\rho$ 为泥石流浆体容重; $C^{*}$ 为颗粒最大体积浓度 $(0.65) ; \Phi$ 为颗粒休止角 $\left(35^{\circ}\right) ; \rho_{\mathrm{d}}$ 为泥石流容重. 据调查泥石流在沟道内和进人邛 海前含有 30\%-40\% 的细颗粒泥沙, 即浆体体积浓度为 $0.3-0.4$, 因此浆体容重为 $1.50-1.66 \mathrm{~g} / \mathrm{cm}^{3}$, 浆 体最大粒径可达 $2 \mathrm{~mm}$. 根据公式( 1 ) - ( 3 ) 计算得: 在鹅掌河中游沟道内时, $\theta=6^{\circ}, \rho_{\mathrm{d}}=1.81-2.00 \mathrm{~g} /$ $\mathrm{cm}^{3}$; 在我掌河下游和河堤内时, $\theta=3^{\circ}, \rho_{\mathrm{d}}=1.66-1.83 \mathrm{~g} / \mathrm{cm}^{3}$; 在鹅掌河人扔海前的扇上时, $\theta=0.32^{\circ}$, $\rho_{\mathrm{d}}=1.52-1.68 \mathrm{~g} / \mathrm{cm}^{3}$. 因此鹅掌河泥石流的容重足以在扔海中以浊流形式运动, 且可以保持稳定运动很 远的距离.

在近 30 年来, 我掌河洪水和泥石流沉积物从大量堆积在原陆地洪积扇上转变为河道型集中地输人邛 海, 人湖后又以浊流型式沿邛海底部边运移边沉积. 图 $2-(\mathrm{b}) \mathrm{B}-\mathrm{B}^{\prime}$ 断面显示, 在 $5746 \mathrm{~m}$ 的长度上平均沉 积厚度 $6.5 \mathrm{~m}$, 表明浊流有较广的沉积范围和较大的沉积厚度, 其中浊流沉积最集中的地方在我掌河河口 正对的水下堤. 由于浊流潜入邛海后, 一方面保持原流势继续运动, 另一方面与湖水掺混、扩散, 可能是 邛海水下堤和水下侵蚀沟漕形成的主要原因之一.

\section{3 结论}

通过扔海和鹅掌河流域的自然、水资源、地理和地质情况, 结合扔海 1988 年和 2003 年水下地形图分 析、研究, 可以得出如下我掌河泥石流对扔海影响的初步结论:

( 1 ) 由于流域内的地质条件, 泥石流固体物质来源丰富, 在洪水, 特别是泥石流暴发时, 我掌河带人 
扔海的泥沙量远较一般土壤侵蚀多.

（2）1975 年起,我掌河洪水和泥石流改由人工固定河堤流人扔海,形成浊流沉积体. 其中鹅掌河口正前 方为浊积物最集中堆积的地带,形成了自南往北廷伸的水下堤以及项海湖底浊积扇陡坡上水下侵蚀冲沟等 水下地形.

(3) 人类活动和鹅掌河洪水、泥石流旺盛堆积作用是扔海湖底近 30 年来地形变化和湖泊基本形态特 征变化的主要原因.

致谢: 本文的研究工作得到了四川省西昌市邛海管理局, 四川省凉山州国土局, 四川省西昌市人大常委会 副主任吴少林, 四川省凉山州防汛办主任肖斌, 西昌市侨联副主席朱江燕等的大力支持和提供的有关资 料, 在此一一表示感谢!

\section{4 参考文献}

[1] 霍坎松, L, 杨松 M 等. 湖泊沉积原理. 郑光鹰译. 北京: 科学出版社, 1992: 4-6.

[2] 中国科学院南京地理与湖泊研究所、兰州地质研究所、南京地质古生物研究所等编. 云南断陷湖泊 环境与沉积. 北京: 科学出版社, 1989: 459-468.

[3] 金相灿等著. 中国湖泊环境, 第三册. 北京: 海洋出版社, 1995: 238-251.

[4] 钱 宁, 万兆惠. 泥沙运动力学. 北京: 科学出版社, 1980: 448-491.

[5] Schwenck T, Spei $\beta$ V, Hubscher C, et al. Frequent channel avulsions within the active channel-levee system of the middle Bengal Fan-an exceptional channel-levee development derived from Parasound and Hydrosweep data. Deep-Sea Research II, 2003, 50: 1023 - 1045.

[ 6 ] Normark W R, Piper D J W, Posamentier H, et al. Variability in form and growth of sediment waves on turbidite channel levees. Marine Geology, 2002, 192 : 23 - 58.

[7] 孙顺才, 张立仁. 云南抚仙湖现代浊流沉积特征的初步研究. 科学通报, 1981, 11:678-681.

[ 8 ] Khripounoff A, Vangriesheim A, Babonneau N, et al. Direct observation of intense turbidity current activity in the Zaire submarine valley at 4000m water depth. Marine Geology, 2003, 194: $151-158$.

[9] YU B. Experimental study on equilibrium concentration of debris flows. International Journal of Sediment Research, 2001, 16( 2 ): $320-325$. 